\title{
Responsabilidade social das empresas e a ong teto: análise crítica
}

Corporate social responsibility and the ceiling: critical analysis

La responsabilidad social corporativa y el techo: análisis crítico

Responsabilité sociale des entreprises et la ong teto : analyse critique

\section{Edmilson Campos Soares e Erika Vanessa Moreira Santos}

\section{(2) OpenEdition}

Journals

\section{Edição electrónica}

URL: http://journals.openedition.org/espacoeconomia/9860

DOI: 10.4000/espacoeconomia.9860

ISSN: 2317-7837

\section{Editora}

Núcleo de Pesquisa Espaço \& Economia

\section{Refêrencia eletrónica}

Edmilson Campos Soares e Erika Vanessa Moreira Santos, « Responsabilidade social das empresas e a ong teto: análise crítica », Espaço e Economia [Online], 16 | 2019, posto online no dia 03 janeiro 2020, consultado o 10 janeiro 2020. URL : http://journals.openedition.org/espacoeconomia/9860 ; DOI : 10.4000/espacoeconomia.9860

Este documento foi criado de forma automática no dia 10 janeiro 2020.

(C) NUPEE 


\title{
Responsabilidade social das empresas e a ong teto: análise crítica
}

\author{
Corporate social responsibility and the ceiling: critical analysis \\ La responsabilidad social corporativa y el techo: análisis crítico \\ Responsabilité sociale des entreprises et la ong teto : analyse critique
}

Edmilson Campos Soares e Erika Vanessa Moreira Santos

\section{Introdução}

1 Nos últimos anos têm-se assistido a uma ampliação das atividades de responsabilidade social e de sustentabilidade empresariais, alargando a atuação do mercado para além dos fatores econômicos clássicos o que, por um lado, age no estancamento das tensões e dos conflitos por meio da captura do padrão de intervenção social nas cidades e, por outro, transforma os temas sensíveis a população carente num bem de valor na reprodução das relações de produção, privatizando as dinâmicas sociais que conformam o espaço urbano.

2 Este trabalho visa compreender a captura do social pelo mercado por meio do discurso da responsabilidade social das empresas, tendo como recorte analítico a ONG Teto e as empresas que financiam suas ações no Brasil. A ONG Teto é financiada por meio de cooperação internacional, doações individuais e, principalmente, por empresas privadas doando bens e serviços para o desenvolvimento do trabalho.

Como procedimentos metodológicos, foram realizadas as seguintes atividades: pesquisa bibliográfica à luz da identificação de elementos que possibilitam entender a racionalidade do financiamento da ONG e a difusão do seu modo de pensar e agir em matéria de política pública e promoção de cidadania; coleta e sistematização de dados secundários a partir de informações disponíveis nos sites das empresas sobre os projetos apoiados, além da realização de entrevistas semiestruturadas com três 
empresas que prestaram apoio a Teto entre os anos 2011-2017 na condição de parceria estratégica e com dois voluntários que colaboram com os trabalhos desenvolvidos pela organização. Como este é um trabalho em desenvolvimento, parte integrante de uma pesquisa de mestrado, nos faltando ainda percorrer alguns trâmites burocráticos e formais, optamos por não citar nominalmente nem as empresas, nem as pessoas entrevistadas.

4 Nossa hipótese é que a política social praticada (ou patrocinada) por essas empresas vem se constituindo como um padrão de intervenção social que visa humanizar o capitalismo, tornando o processo de globalização mais passivo de aceitação. As empresas procurariam, por meio da chamada responsabilidade social, aproximar-se da força dos lugares e dela tirar vantagens mercadológicas, utilizando-se da questão social como um ativo financeiro dentro do sistema concorrencial capitalista e na formação de sua imagem corporativa.

5 A chamada responsabilidade social empresarial se consolida como importante estratégia empresarial, ao se colocar como produtora de uma sociabilidade nos lugares de sua atuação, revelando-se fundamental para a compreensão da urbanização contemporânea por lógicas que buscam a realização do espaço enquanto negócio. Dessa forma, a classe que detém a maior parte dos recursos pode influenciar, por meio da relação monetária, a ocupação, modelagem e a fragmentação do espaço da forma que melhor lhe convém. É necessária uma compreensão de como o capital, crescentemente - e diversamente com essas novas estratégias -, domina o espaço para que temas como a estruturação do espaço urbano, a segregação socioespacial e a fragmentação desse espaço possam ser devidamente tratados.

6 Além desta introdução, o texto está estruturado em outros três momentos. 0 primeiro consiste em nossa fundamentação teórica, onde buscamos compreender a realização das práticas de responsabilidade social das empresas enquanto estratégias mercadológicas, que produzem uma sociabilidade que conformam um padrão de intervenção social, corroborando a lógica e o entendimento de apropriação da cidade e do espaço urbano enquanto negócio. No segundo momento, apresentamos uma discussão acerca da responsabilidade social das empresas e do terceiro setor, procurando demonstrar como essa política empresarial vem se mostrando funcional a reprodução do espaço enquanto mercadoria por meio dessas novas práticas. Por último, passamos para a análise de nosso objeto de estudo, a ONG Teto e seus financiadores, apresentamos e debatemos os resultados obtidos com a coleta e sistematização de dados secundários e também dos resultados colhidos nas entrevistas semiestruturadas.

7 Constatou-se, no andamento dessa pesquisa, que a ação social das empresas está concentrada nos ramos de sua atuação comercial; que há um forte incentivo da participação de seus funcionários como voluntários nas causas apoiadas e que essas ações são de grande interesse de um marketing social que visa o fortalecimento da imagem corporativa da empresa, denotando, assim, o que mais parece ser uma captura de pautas e políticas sociais, por meio das quais se reforçam os ideais de empreendedorismo, privatismo e mercadificação do que propriamente iniciativas que visam à redução da desigualdade ou que acenem para a promoção da cidadania. Em outras palavras, a questão social, como qualquer outra mercadoria no rol da reprodução capitalista, passa a fazer parte de um modelo de negócios como um "negócio social" corroborando para a perspectiva do espaço (e da cidade) enquanto mercadoria (CARLOS, 2018). 


\section{A cidade como negócio: a captura da intervenção social}

O espaço e, em especial, o espaço urbano, é indispensável à reprodução das relações sociais, não apenas por ser produto social, mas como condição e meio de toda a dinâmica de realização da sociedade, refletindo, inclusive, suas contradições. Ao longo da história do modo de produção capitalista, o espaço urbano vem sendo crescentemente inserido nos circuitos de valorização do capital, seja como suporte às atividades econômicas por meio da implementação de infraestruturas e desenvolvimento técnico que possibilitam maior fluidez das atividades, seja por meio da mercantilização do próprio espaço e das dinâmicas sociais que o conformam.

9 Segundo Lefebvre (1999):

[...] o capitalismo [...] encontrou um novo alento na conquista do espaço, em termos triviais na especulação imobiliária, nas grandes obras (dentro e fora das cidades), na compra e venda do espaço. E isso à escala mundial. [...] A estratégia vai mais longe que a simples venda, pedaço por pedaço, do espaço. Ela não só faz o espaço entrar na produção da mais-valia, ela visa uma reorganização completa da produção subordinada aos centros de informação e decisão. (LEFEBVRE, 1999, p.142).

10 A mercantilização da terra urbana (parcelamento, loteamento ou verticalização), a crescente inclusão do espaço urbano nos circuitos do capital financeiro e até a captura do padrão de intervenção social nas cidades - como pretendemos demonstrar nesse texto -, evidenciam que o espaço urbano se tornou um elemento estratégico para a acumulação de capital. Botelho (2007), ressalta que dentro do sistema capitalista toda a produção e consumo do espaço, assim como a própria urbanização, estão inseridos nesse amplo processo de reprodução das relações capitalistas:

À dimensão utilitária do espaço, que o torna um valor de uso para a sociedade, se sobrepõem determinações históricas da produção e da reprodução social, as quais, sob a vigência das relações capitalistas de produção, sintetizam o valor de troca e o valor de uso. 0 valor de troca se sobrepõe historicamente ao valor de uso, o que significa que, para se usufruir determinados atributos do lugar é preciso que se realize, antes de tudo, seu valor de troca (BOTELHO, 2007, p.23).

11 Já Carlos (2005) reforça que:

o consumo do espaço se analisa no movimento de generalização da transformação do espaço em mercadoria, que impõe ao uso a existência da propriedade privada das parcelas do espaço. Assim, o processo de reprodução do espaço aponta para a tendência da predominância da troca sobre os modos de uso, o que revela o movimento do espaço de consumo para o consumo do espaço (CARLOS, 2005, p. 186).

12 O que buscamos aqui é, portanto, assinalar o deslocamento da dinâmica socioespacial de produção dos objetos e das coisas no espaço - e das atividades nele localizadas - para a produção do espaço. A cidade torna-se produto e, ao mesmo tempo, condição e meio da equação de realização do ciclo do capital. Isso significa o abandono da concepção de cidade apenas como lugar dos negócios para uma compreensão de que a cidade se tornou, ela própria, um objeto lucrativo dos grandes negócios. (CARLOS, 2005; LEFEBVRE, 1999).

13 É importante ressaltar ainda que esse movimento se dá em conformidade aos novos paradigmas da economia em sua fase denominada globalizada. A estrutura organizacional da produção fordista foi substituída pela flexibilização da estrutura produtiva fazendo emergir como grande protagonista a corporação transnacional, 
desenhando novas estratégias de governança baseadas na flexibilização das relações capital-trabalho, nas desregulamentações e nas privatizações de serviços públicos e na facilitação da circulação de capitais entre nações, enquanto atividades não-estatais e novas estratégias espaciais são postas à operar em favor da criação de novos vínculos entre o espaço e o capital (MARICATO, 2015).

Por outro lado, essa nova orientação da política vai significar também o desmanche das alternativas abertas com as lutas populares que culminaram na Constituição de 1988. Enquanto o período precedente havia sido de otimismo e entusiasmo com o fim do regime militar e as possibilidades de discussão dos rumos do país, o período pósredemocratização foi de perplexidade e descrença, com a hegemonia do capital e a ratificação e aprofundamento das desigualdades. Atualmente, podemos falar de novas formas de pobreza, em que são reforçados os sujeitos como consumidores, mas não a cidadania.

Diante desse quadro, a sociedade civil organizada passa a desenvolver um novo perfil de atuação, bastante estreito com empresas e agências financiadoras ligadas ao grande capital, que em conjunto são chamadas a "cuidar" do social e a assumir um novo papel como mitigadoras dos problemas sociais, por meio do polo associativo do terceiro setor e da chamada "responsabilidade social das empresas".

Segundo Santos (2000):

A política agora é feita no mercado. Só que esse mercado global não existe como ator, mas como uma ideologia, um símbolo [...] agora se fala muito num terceiro setor, em que as empresas privadas assumiriam um trabalho de assistência social antes deferido ao poder público. Caber-lhes-ia, desse modo, escolher quais os beneficiários, privilegiando uma parcela da sociedade e deixando a maior parte de fora. Haveria frações do território e da sociedade a serem deixadas por conta, desde que não convenham ao cálculo das firmas. Essa "política" das empresas equivale a decretação de morte da Política (SANTOS, 2000, p.67)

17 Apesar do discurso de mudança social, a política social praticada (ou patrocinada) por essas empresas vem se constituindo, conforme Santos (2014), como uma psicosfera que visa humanizar o capitalismo, tornando o processo de globalização, destituidor das identidades e políticas sociais, mais passível de aceitação, além de usar a questão social como vantagem competitiva no sistema concorrencial capitalista e na formação de sua imagem corporativa.

A receita para a empresa se distinguir na renhida batalha do mercado globalizado continua a conter os ingredientes clássicos: qualidade total, reengenharia, relação custo-benefício, compromisso com o cliente etc. Entretanto, será mais "palatável" a empresa que incorporar uma boa dose de cumplicidade com seu entorno, evidenciada num programa de atuação comunitária (MARTINELLI, 1997, p.81, grifo nosso).

Daí o porquê destas corporações passarem a figurar crescentemente em ações de cunho social que acabam por incluir, justamente, a gestão de parte da demanda social originada pela própria expansão global das empresas, bem como das soluções à crise que adotam, como descrito por Arantes et al (2000), o pensamento único na cidade.

Para Arantes (2000), o processo descrito aqui pode ser chamado de uma nova forma de "gentrificação estratégica". Segundo a autora, é preciso distinguir acima do alicerce formado pelos fatores econômicos clássicos sobre os quais se produz o espaço urbano terra, trabalho e capital - as camadas "simbólicas" que consistem na manipulação da produção do espaço, que vão desde linguagens simbólicas de exclusão e habitação, 
passando por uma "economia simbólica" do empreendedorismo, até a maneira pela qual se permite, por assim dizer, "manusear" o espaço, ou seja, as novas formas de intervenção no espaço que essas camadas simbólicas irão autorizar.

[...] não se trata de constatar a colonização da animação cultural (que aliás já nasceu colonizada, como o próprio nome indica) pela Máquina de Crescimento, mas sobretudo a operação inversa: o novo combustível sem o qual a coalizão não fabrica os consensos de que necessita, pois se trata de uma máquina ideológica acionada pelos que administram tanto a construção física quanto a ideacional dos recursos capazes de impulsionar o desenvolvimento dentro e através dos "lugares" da cidade (ARANTES, 2000, p. 29).

\section{E ainda:}

[...] não só como cidade-negócio, mas igualmente como uma cidade "polida" em todas as suas engrenagens - de uma vendedora de bontique a um transeunte benévolo como se vivesse numa ONG de asfalto - como uma só empresa regida por um script único de atendimento ao cliente, como em qualquer lanchonete de fastfood. (ARANTES, 2000, p.38).

Portanto, isso significa avançar sobre os lugares das metrópoles, submetendo-os a uma gestão do espaço, incluindo aí o padrão de intervenção social nas cidades, que passa a ser entendido (e controlado) sob a égide da reprodução do capital, acentuando disparidades, em decorrência das estratégias espaciais que compõem o ajuste realizado pelas empresas (CORREA, 1992).

A produção do espaço se coloca como uma noção estratégica para nossa compreensão do mundo, pois ela potencializa a reflexão sobre a práxis, sobre os múltiplos e contraditórios processos e relações sociais que estão em transformação constante e que se reproduzem espacialmente, revelando, portanto, os próprios fundamentos da reprodução da sociedade em sua concretude (que abriga também as ideologias, as representações). A análise da produção do espaço permite "desabsolutizar" aquilo que aparece como o novo absoluto - os novos espaços, as novas práticas, as novas representações (CARLOS, 2018 p.7).

A construção da dimensão social da empresa, através da responsabilidade social, tem como objetivo assegurar a ampliação da sua força política, oferecendo à corporação certa "legitimidade" social que falta à sua dimensão econômica. Ou seja, a chamada responsabilidade social empresarial se consolida, assim, na empresa contemporânea como importante estratégia empresarial, ao se colocar como produtora de uma sociabilidade nos lugares de sua atuação, relevando-se fundamental para a compreensão da urbanização contemporânea por lógicas que buscam a realização do espaço enquanto negócio.

\section{Responsabilidade social das empresas e o terceiro setor}

Ainda que seja uma prática antiga, com mudanças de conteúdo ao longo da história, é só mais recentemente que a responsabilidade social das empresas e o terceiro setor tomam grandes proporções e vem ganhando destaque.

24 A ideia de responsabilidade empresarial não é novidade e está ligada nos seus primórdios à filantropia de base religiosa no começo do século XX. Pereira (2007, p. 10-11) faz uma distinção da forma como se deu a noção de responsabilidade social empresarial no Brasil em três períodos.

O primeiro período compreende o período até a década de 1930, no qual as benesses oferecidas pela empresa a seus funcionários eram dadas na condição de "favor pessoal", 
sem interferência ou mediação do Estado, principalmente nas regiões mais afastadas dos grandes centros.

Já o segundo período estende-se até meados da década de 1980, e é marcado, segundo a autora, pela difusão de uma racionalidade cientifica, segundo a qual as empresas deveriam obter o controle em todos os âmbitos da vida de seus funcionários, formando o mercado consumidor necessário para a industrialização crescente da época. É também nesse período que as empresas passam a constituir fundações próprias, especializadas nas normatizações da relação entre empresas e comunidade. No terceiro e atual período, cresce também o número de certificações e premiações privadas, configurando uma lógica de normatização à parte do Estado.

Há ainda que se pontuar a existência de uma grande heterogeneidade no uso de termos e expressões que se relacionam a essas práticas, mas que, ao fim e ao cabo, dizem respeito ao mesmo fenômeno. Enquanto, numa ponta, expressões como "filantropia corporativa", "investimento social privado", "marketing social", "responsabilidade social das empresas"; "desenvolvimento sustentável" e/ou "sustentabilidade dos negócios" são usadas para designar, no plano discursivo, as justificativas dessas práticas, outras expressões como "organização da sociedade civil de interesse público", "organizações não-governamentais, "associações sem fins lucrativos", "fundações empresarias" e "terceiro setor" são usadas, na outra ponta, para fazer referência à institucionalização das práticas concretas realizadas (PEREIRA, 2007).

Apesar da constatação de práticas empresariais ao longo desses períodos históricos, entendemos que é com as reformas implantadas no país a partir de 1990 que essas ações ganham uma nova dimensão, servindo como difusoras dessa "nova política" de redução da intervenção do Estado e da diminuição da responsabilidade pública ante ao crescimento da responsabilidade empresarial privada.

Essa concepção de que os empresários devem "fazer sua parte" na construção de uma sociedade justa e democrática acaba por justificar seu engajamento no combate às desigualdades sociais e a pobreza, um combate que deve ser levado a cabo pela implementação de projetos sociais gerenciados por entidades privadas.

Para Maranhão (2011):

Esse compromisso atravessa as noções de filantropia, investimento social privado, responsabilidade social e desenvolvimento sustentável. A filantropia tradicional na forma de contribuições pontuais - é cada vez mais substituída por ações norteadas por um plano de ação e um raciocínio de minimização de gastos e maximização de retorno. São ações focalizadas, cujo resultados devem ser avaliados e monitorados. A mudança da filantropia tradicional para um planejamento racional das ações expressa os componentes da gramática política que dá nova forma à ação social (MARANHÃO, 2011, p. 244).

31 Além disso, a filantropia empresarial, ao adotar iniciativas voltadas ao desenvolvimento de solidariedade social, tende a utilizar as organizações sem fins lucrativos com um espaço estratégico dentro do sistema concorrencial capitalista:

$\mathrm{Na}$ atualidade, o acirramento da concorrência tem conduzido o empresariado a estratégias que otimizem não somente seus processos produtivos, mas toda comunidade que o circunda. Ou seja, conforme a atual dinâmica do campo econômico, são promovidas as iniciativas que rompam as fronteiras entre as práticas internas e externas das organizações, criando condições do produto ser produzido e consumido, despertando o interesse de investidores, colaboradores e consumidores. Daí as práticas de interação com escolas, hospitais ou OSCIPs, dinamizando as relações entre os campos social e econômico, sob a denominação de 
filantropia empresarial: termo relacionado à estratégia e ao uso estratégico da filantropia, defendido como uma vantagem competitiva para as empresas (PINHEIRO, 2002, p.35).

\section{Ou como defende Montaño (2002), algumas fundações e empresas}

[...] não podem esconder seu claro interesse econômico por meio da isenção de impostos ou da melhora de imagem de seus produtos (aumentando a venda ou o preço) ou até na função propagandística que estas atividades exercem. Têm, portanto, claro fim lucrativo, ainda que indireto (MONTAÑO, 2002, p. 58).

Uma das formas que mais tem catalisado esses empreendimentos da responsabilidade social empresarial é o polo associativo do terceiro setor. Um "terceiro setor" que pode ser definido como aquele em que as atividades não são organizadas ou forçadas pelo Estado (primeiro setor) e nem voltadas ao lucro como no mercado (segundo setor).

Pode-se dizer que o terceiro setor é composto por organizações sem fins lucrativos criadas e mantidas pela ênfase na participação voluntária, num âmbito nãogovernamental, que dão continuidade às práticas tradicionais da caridade, da filantropia e do mecenato e expandem seu sentido para outros domínios, graças, sobretudo, à incorporação do conceito de cidadania e de suas múltiplas manifestações na sociedade civil. (FERNANDES, 1997, p.27).

\section{Para Cardoso (1997), o terceiro setor é}

[...] um espaço de participação e experimentação de novos modos de pensar e agir sobre a realidade social. Sua afirmação tem o grande mérito de romper a dicotomia entre público e privado, na qual público era sinônimo de estatal e privado de empresarial. Estamos vendo o surgimento de uma esfera pública não-estatal e de iniciativas privadas com sentido público. Isso enriquece e complexifica a dinâmica social (CARDOSO, 1997, p. 7).

Apesar das definições acima citadas considerarem o terceiro setor como uma representação de novos espaços institucionais que agregam à dinâmica social, elas carregam também, a nosso ver, o mascaramento de que a sociedade civil é diminuída a condição de terceiro setor, nem público nem privado, algo composto por um conjunto de entidades e que "passa por cima das clivagens de classe, da diversidade dos projetos políticos, dos conflitos sociais, para valorizar a ideia da comunidade abstrata, das relações de ajuda mútua, de solidariedade social" (RAICHELIS, 2006 p.24).

De acordo com Montaño (2002):

[...] o objetivo de retirar o Estado (e o capital) da responsabilidade de intervenção na "questão social" e de transferi-los para a esfera do "terceiro setor" não ocorre por motivos de eficiência (como se as ONGs fossem naturalmente mais eficazes que o Estado), nem apenas por razões financeiras: reduzir os custos necessários para sustentar esta função estatal. O motivo é fundamentalmente político-ideológico: retirar e esvaziar a dimensão de direito universal do cidadão quanto a política sociais (estatais) de qualidade; [...] desonerar o capital de tais responsabilidades, criando, por um lado, uma imagem de transferência de responsabilidades e, por outro, a partir da precarização e focalização (não universalização) da ação social estatal e do "terceiro setor", uma nova e abundante demanda lucrativa para o setor empresarial (MONTAÑO, 2002, p.23).

Para Rizek (2011), esse conjunto de processos se constitui como uma nova forma de gestão da pobreza, pois se trata de um novo acoplamento entre a questão social (condições precárias de vida e de trabalho, pobreza urbana, situações periféricas como moradias precárias que se fazem acompanhar de acesso nem sempre fácil aos serviços urbanos) e a proposição de políticas públicas e práticas culturais que 
[...] apontam para um modo novo de configuração da questão e da gestão da vida e da vida urbana, na perspectiva da acomodação, do apaziguamento e da pacificação, na chave de uma elisão da possibilidade do conflito e de formação de sujeitos capazes de ação política, o que despolitizaria crescentemente o horizonte e a vida na cidade (RIZEK, 2011, p.5). premiada pela ONU-Habitat por suas práticas de assentamentos humanos, prêmio que voltou a receber nos anos de 2010 e 2012. Em 2017 foi uma das finalistas do Prêmio Mundial do Habitat, reconhecimento concedido anualmente pela Fundação de Construção e Habitação Social (BSHF) à projetos que apresentem práticas para os problemas habitacionais em todo o mundo. Além desses, a Teto possui diversos outros prêmios de entidades privadas nos países em que atua. 

esforços do modelo de intervenção da organização se concentram em atender às necessidades comunitárias, principalmente por meio da construção de moradias de emergência. A organização acredita que a construção das casas de emergência funciona não apenas como uma forma de entrar na comunidade e ganhar sua confiança, mas, principalmente, como uma maneira de denunciar a pobreza existente no país, por meio da conscientização de seus voluntários e da aparição na mídia. O processo de construção das casas pressupõe várias etapas, começando com a seleção das comunidades que serão atendidas. Depois de definidas as comunidades, começa o processo de seleção das famílias, seguido da convocação dos voluntários e, finalmente, o evento da construção, que acontece, geralmente, em um final de semana. o modelo de intervenção está em constante mudança, sendo também admitido que o modelo de trabalho é bastante "quadradinho" adotando certas posturas apenas porque deram certo no Chile. Numa consulta pelos sites da ONG Teto do Chile, Bolívia e Argentina, percebemos que o modelo de intervenção é basicamente o mesmo, com pouca ou nenhuma distinção daquele que é adotado no Brasil, o que coloca uma questão importante: como um processo que está totalmente atrelado à dinâmica de um determinado país, sua conjuntura política, seu histórico e suas necessidades habitacionais e sociais, pode ser transposto para outro país, baseado em normas gerais?

Essa problemática fica expressa na rapidez com que a ONG se expandiu no Chile e os resultados lá atingidos, contra a dificuldade encontrada para a sua expansão no Brasil. Por aqui, a Teto mantém um trabalho bastante concentrado nas cidades e regiões metropolitanas do sul e sudeste. É da própria ex-diretora a constatação de que isso acontece devido às diferenças existentes entre as comunidades necessitadas no Chile, nos demais países e as existentes aqui, especialmente aquelas localizadas nas regiões metropolitanas. Enquanto no Chile as comunidades são basicamente rurais, com poucas famílias, localizadas em terrenos amplos e de propriedade legal, a situação nas metrópoles brasileiras é praticamente oposta: comunidades com centenas de famílias, incrustadas em áreas urbanas superadensadas, em terrenos ocupados ilegalmente e em áreas de risco.

47 Além disso, aqueles que são atendidos precisam arcar ainda com um custo de $R \$ 200,00$ (duzentos reais), o qual deve ser pago antes da construção. Sobre esses valores, a justificativa da ONG para o estabelecimento dessa quantia é "dar poder à família, para que ela se sinta responsável pelo seu próprio desenvolvimento, valorize sua nova moradia e de todo o processo da construção" (TETO, 2011, p. 12). Esse valor, no entanto, é instituído de forma aleatória, sem qualquer estudo sobre o impacto dessa quantia no orçamento das famílias. E o mais curioso, a nosso ver, é que tal justificativa transparece uma visão preconceituosa e meritocrática da situação precária em que se encontram essas pessoas. É preciso que elas contribuam pois "não se pode dar tudo de graça", como se as famílias estivem nessa situação por indolência. É no mínimo irônico querer "denunciar a pobreza" ou defender a necessidade de conscientização das pessoas quando seu próprio modelo de trabalho exclui aqueles que não podem se inserir no mercado da intervenção social, colocando essas pessoas numa situação de passividade perante sua realidade.

48 Em outra entrevista, com o diretor de gestão comunitária da ONG Teto, também realizada em 2016, ficou evidente que, apesar de se colocar como realizadora de 
projetos nas comunidades, a ONG prioriza a seleção daquelas que optam pela construção das casas de emergência, pois, geralmente, essa é uma das urgências mais gritantes dentro das comunidades e também porque, segundo ele, trata-se de uma "coisa pop", ou seja, a construção das casas é um processo palpável, que pode ser mensurado e gera resultados passíveis de serem apresentados na mídia e aos financiadores, o que vai no mesmo sentido apontado por Gohn (2008) de que a dependência de recursos disponíveis e a disputa por financiamentos, acirram a competitividade nos trabalhos realizados, fazendo com que as ONGs se tornem bastante pragmáticas, procurando qualificar os "serviços prestados". Os trabalhos passam a se concentrar em projetos e programa focalizados para "clientelas" específicas, na busca por resultados satisfatórios, como numa empresa privada (GOHN, 2008, p.56).

Para Abílio (2011), essa é uma característica comum às ONGs. A autora chama atenção ainda para o fato de que a responsabilidade dessas instituições não está fundamentalmente relacionada com aqueles que atingem, mas sim com aqueles que as financiam, que podem ser os mesmos que "lucram com a desigualdade social, precarizam o trabalho e geram o desemprego". (ABILIO, 2011, p. 314).

Isso fica demostrado inclusive num documento denominado "carta de projetos" da Teto. Nele, a instituição faz um apelo de marketing empresarial relacionado à causa: "vincule sua marca à causa de superação da pobreza, reforçando sua preocupação com a sociedade, transmitindo sua atuação na área de responsabilidade social para seus públicos" (TETO, 2016, p.5).

51 A organização se financia por meio de doações empresariais, cooperação internacional e doações de pessoas físicas. Segundo o último relatório de atividades (TETO, 2017), a ONG Teto conta com 51 empresas parceiras, sendo: 8 delas em "parceria estratégica", que doam bens, serviços e recursos financeiros para o desenvolvimento do trabalho; 33 empresas com voluntariado corporativo, que estimulam seus funcionários a participar voluntariamente na construção de casas de emergências e ainda outras 10 empresas como "amigas Teto" que apoiam seus projetos com doações mensais (Quadro 1).

Quadro - Parcerias Teto do ano de 2017

\begin{tabular}{|r|l|}
\hline & Casas Bahia, ABN-AMRO, Adobe, AECOM, Assist Card, Bain \\
\& Company, BASF, Burson-Masteller, BNP Paribas, Bolos das \\
Meninas, Lockton, Kasznar Leonardos, Design Techo, Civil \\
Organizaçõ \\
es Associadas \\
Construtora eEmpreendimentos, DHL, ePharma, Euzaria, Deutsche \\
Bank, FedEx, GFK, Instituto C\&A, GE Volunteers, Turner, \\
Simpress, Nokia, Guardex, iZettle, Oceânica, Atento, Marriott, \\
Swiss Re Foundation, HP Enterprise, JHSF, JBS Couros, Servier, \\
MetLife, TFG, Instituto Legado, Jubilut Junior, Swarovski, \\
StiboSystemns, Nice, VF Corporation.
\end{tabular}

FONTE: TETO (2017) ORg.: Edmilson Campos Soares 
Com isso, o aporte financeiro de doações de pessoas jurídicas da ONG Teto cresceu de forma bastante significativa ao longo dos últimos anos, 2011 a 2015, como podemos verificar na tabela 01 .

Tabela 1 - Doações empresariais (2010-2015)

\begin{tabular}{c|c}
\hline Ano & Valor (RS) \\
\hline 2010 & 131,138 \\
\hline 2011 & 878,424 \\
\hline 2012 & 902.941 \\
\hline 2013 & 1.247 .226 \\
\hline 2014 & 880,205 \\
\hline 2015 & 2.028 .845 \\
\hline
\end{tabular}

FONTE: Site da ONG Teto ORg.: Soares (2016)

Não há dados publicados para o ano de 2016 e o relatório de balanço financeiro para o ano de 2017, último disponível no site da ONG Teto, apresenta apenas a informação de que $19 \%$ do total arrecadado vieram de doações empresariais, sem especificar, no entanto, o valor total da arrecadação para o ano.

4 Em relação às empresas entrevistadas foi possível delinear alguns traços comuns à sua atuação social a partir dos dados secundários. As três empresas que constam como "parceiras estratégicas" da ONG e que foram objeto de análise desse estudo, mantêm uma página ou um site dedicado às suas ações de responsabilidade social, exaltando os "valores" e as "missões" das empresas comprometidas eticamente com um "mundo melhor". É comum nessas páginas discursos genéricos e difusos, utilizando termos de marquetagem como "empresa do bem", "eticamente ou socialmente comprometida" ou ainda, quando da questão do meio ambiente, "ecologicamente correta" ou “sustentável".

Outra característica comum é que todas elas apresentam, de maneira mais ou menos destacada, um "balanço social" que também pode aparecer com o nome de "balanço de ações”. Trata-se de uma ferramenta utilizada para propagar as políticas empresariais, a partir da publicização das ações sociais das empresas. É uma espécie de prestação de contas daquilo que a empresa faz por responsabilidade social, sugerindo a transparência e o compromisso do seu trabalho. Contudo, como não há uma padronização desses balanços, o uso dessa ferramenta pelo interesse público é inócuo, servindo, apenas, de material argumentativo-persuasivo.

Já nas entrevistas, realizadas entre fevereiro e abril de 2019, com os seus representantes pelo setor de responsabilidade social, setor esse quase sempre alocado junto ao setor de marketing das empresas, foi possível compreender outros aspectos. Em primeiro lugar, ficou evidente em nossas conversas com um dos representantes das empresas que as ações sociais foram estrategicamente pensadas e articuladas aos seus modelos de negócio. Um dos nossos entrevistados chega a afirmar, categoricamente, 
que apenas ações sociais que estejam inseridas dentro do modelo de negócios da empresa, e somente nos países e nas regiões onde a empresa tem relevância é que podem vir a receber apoio, dentro da concepção de que a questão social transformou-se num "negócio social" - expressão que o próprio entrevistado utilizou para se referir aos projetos que recebem o apoio da empresa.

Chamou a atenção também as falas de que o aspecto mais relevante, ainda que haja o interesse financeiro, não é uma eventual dedução de imposto de renda ou incentivos fiscais, mas sim, o "selo de empresa do bem", que, segundo um dos entrevistados, tem mais importância em alguns nichos de mercado e traz mais retorno do que qualquer dedução ou incentivo fiscal.

Sobre o modelo de intervenção e a relevância do trabalho realizado pela ONG Teto, os representantes das empresas concordam que os resultados são pontuais, focalizados e que não têm a pretensão de resolver um problema estrutural e complexo, como é o da questão habitacional e da segregação socioespacial, mas, segundo eles, o trabalho desenvolvido pode contribuir para a mobilização e engajamento, melhorando a vida das pessoas. Provocados a dar opinião sobre o motivo pelo qual a ONG atua mais nas cidades e regiões metropolitanas das regiões sul e sudeste do Brasil do que nas demais regiões do país, um dos nossos entrevistados afirmou que acredita que o motivo seja a grande predominância de áreas de favelas nessas regiões bem como a possibilidade de atingir um maior público com as divulgações dos trabalhos. Os outro dois representantes preferiram não opinar.

Outro traço comum e que acabou se relevando de maneira até inesperada nas entrevistas foi o da importância dada ao voluntariado coorporativo. As três empresas afirmaram que a possibilidade de seus funcionários atuarem como voluntários é determinante para que as organizações possam receber seu apoio. Uma delas, inclusive, disse usar o grau de engajamento e participação de seus funcionários como um dos requisitos para a progressão de carreira. Acreditamos que esse ponto ainda precisa ser melhor investigado, no entanto, parece ocorrer aqui aquilo que Antunes (2018) chama de "o privilégio da servidão" uma vez que a utilização desse voluntariado coorporativo se dá como um ativo das empresas nas ações apoiadas, denotando uma relação de coisificação da mão de obra sob o argumento da solidariedade social.

Entendemos, portanto, que a prática da responsabilidade social das empresas denotam um contexto onde empresários e a sociedade civil organizada são chamados a "cuidar" do social a partir do deslocamento da noção de pobreza como construção política para o terreno da administração da questão social a partir da solidariedade privada e da filantropia, o que vai ao encontro à adoção de soluções de mercado como eixo organizador da vida social e política, reduzindo o papel do Estado, com o objetivo de prover uma estrutura para o mercado e oferecer serviços que o mercado não pode (ou não tem interesse de) atender.

61 Dessa forma, a produção do espaço enquanto mercadoria pela prática da responsabilidade social das empresas pressupõe a produção induzida de uma sociabilidade mercadológica que, legitimada por meios persuasivos, autorizam um padrão de intervenção social nas cidades guiado pelo privatismo e mercadificação, transformando a própria segregação socioespacial num bem financeiro a ser computado na reprodução das relações de produção. 


\section{Considerações finais}

62 demanda grande esforço metodológico, tendo em vista, tal como descrito por Santos (2014), a força que o senso comum emprega para construir e efetivar essa psicoesfera funcional à reprodução ampliada do capital, criando ordenamentos políticoinstitucionais e espaciais. espaço enquanto matéria-prima do processo de reprodução ampliada de capital vai envolver novas estratégias de gestão que, por um lado, busca gerir conflitos e resistências aos ditames do ajuste econômico e, por outro, transforma as dinâmicas sociais em vantagens competitivas para as empresas por meio de uma solidariedade interesseira. Para tanto, mais do que fotos de crianças estudando e trabalhadores sorrindo nas ilustrações de balanços sociais é necessário que a vida cotidiana das pessoas seja impactada positivamente, nos parecendo aquilo que Freire (2005) chama de "falsa generosidade", ou seja, a construção de uma relação solidária do opressor para com o oprimido no objetivo de reproduzir, justamente, a relação de opressão.

Já do lado da ONG Teto nos parece bastante evidente que ela está imersa numa contradição: sustentar-se no discurso da denúncia e do enfretamento da pobreza extrema promovendo soluções habitacionais, ao mesmo tempo que persegue esses objetivos totalmente na lógica de soluções pelo viés do mercado, seguindo o modelo padrão da gestão por resultados, preocupada em bater metas e apresentar "coisas pop" que, junto com sua extensa divulgação e marketing, qualificariam seu trabalho perante aqueles que a subsidiam, dentro dos princípios da eficiência técnica e eficácia, características do projeto neoliberal.

O trabalho apresentado buscou contribuir para o debate da responsabilidade social das empresas no campo geográfico, à luz de uma discussão que perpassa a cidade enquanto negócio, sob a égide do capital financeiro.

\section{BIBLIOGRAFIA}

ARANTES, Otília et al. A cidade do pensamento único: desmanchando consensos. Rio de Janeiro: Vozes, 2000.

ABÍLIO, Ludmila. A gestão do social e o mercado da cidadania. In: CABANES, Robert (org.). Saídas de emergência: ganhar/perder a vida na periferia de São Paulo. São Paulo: Boitempo, 2011, p. 292-307.

BOTELHO, Adriano. 0 urbano em fragmentos: a produção do espaço e da moradia pelas práticas do setor imobiliário. São Paulo: Fapesp, 2007.

CARDOSO, Ruth. Fortalecimento da sociedade civil. In: IOSCHPE, Evelyn Berg (org.). 3o setor:

desenvolvimento social sustentado. São Paulo: Paz e Terra, 1997, p. 7-12. 
CARLOS, Ana Fani Alessandri. A cidade como negócio. São Paulo:Contexto, 2018

. (org). Novos caminhos da geografia. São Paulo:Contexto, $5^{\text {a }}$ ed. 2005.

CORREA, Roberto Lobato. Corporação, práticas espaciais e gestão do território. Revista Brasileira de Geografia, Rio de Janeiro, v.54, n. 3, 1992.

FERNANDES, Rubem César. O que é o terceiro setor? In: IOSCHPE, Evelyn Berg (Org.). 3os setor: desenvolvimento social sustentado. São Paulo: Paz e Terra, 1997, p.25-33.

FREIRE, Paulo. A Pedagogia do Oprimido. 42ª ed. Rio de Janeiro: Paz e Terra, 2005.

GOHN, Maria da Glória. 0 protagonismo da sociedade civil. $2^{2}$ ed. São Paulo: Cortez, 2008.

LEFEBVRE, Henri. A Revolução Urbana. Belo Horizonte: UFMG, 1999.

MARANHÃO, Tatiana de. O sentido político das práticas de responsabilidade social no Brasil”, In: CABANES, Robert (org.). Saídas de emergência: ganhar/perder a vida na periferia de São Paulo. São Paulo: Boitempo, 2011, p.237-256.

MARICATO, Ermínia. Para entender a crise urbana. São Paulo: Expressão Popular, 2015.

MARTINELLI, Antônio Carlos. Empresa-cidadã: uma visão inovadora para uma ação transformadora. In: IOSCHPE, Evelyn Berg (org.). $3^{\circ}$ setor: desenvolvimento social sustentado. São Paulo: Paz e Terra, 1997.

MONTAÑO, Carlos. Terceiro Setor e Questão social: crítica ao padrão emergente de intervenção social. São Paulo: Cortez, 2002.

PEREIRA, Evellyn. A empresa e o lugar na globalização: A “Responsabilidade Social Empresarial" no território brasileiro. Dissertação de (Mestrado em Geografia) da Faculdade de Filosofia, Letras e Ciências Humanas da Universidade de São Paulo - USP, 2007.

PINHEIRO, Leandro Rogério. Gestão de voluntários, ações em rede: análise de dois casos em Porto Alegre. Dissertação (Mestrado em Administração). Porto Alegre: Escola de Administração da Universidade Federal do Rio Grande do Sul, 2002.

RAICHELIS, Raquel. Gestão pública e a questão social na grande cidade. Revista Lua Nova, v. 69, 2006, p.13-68.

RIZEK, Cibele. Práticas Culturais e ações sociais: as novas formas de gestão da pobreza. XIV Encontro Nacional da ANPUR, Rio de Janeiro, Brasil, 2011, p.1-20.

SANTOS, Milton. A natureza do espaço: técnica e tempo, razão e emoção. São Paulo:Edusp, 4⿳⺈冂a ed. 2014.

Por uma outra globalização: do pensamento único à consciência universal. Rio de Janeiro: Record, $22^{\mathrm{a}}$ ed. 2012.

SOARES, Edmilson Campos. Habitação e Terceiro Setor: novas formas de gestão da pobreza no núcleo Cata-Preta, Santo André (SP). Trabalho de Conclusão de Curso. Ourinhos: Universidade Estadual Paulista "Júlio de Mesquita Filho" - UNESP, Campus de Ourinhos, 2016.

TETO. Relatório de atividades. 2011. Disponível em: <www.techo.org/paises/brasil/teto/ transparencia>. Acesso em: 21 de outubro de 2016.

Relatório de atividades, 2016. Disponível em: <www.techo.org/paises/brasil/teto/ transparencia/>. Acesso em: 21 de outubro de 2016.

. Relatório de atividades. 2017. Disponível em: <www.techo.org/paises/brasil/teto/ transparencia>. Acesso em: 21 de abril de 2019. 


\section{NOTAS}

1. https://www.techo.org/brasil/

\section{RESUMOS}

Este trabalho tem como objetivo central entender a captura do social pelo mercado por meio do discurso da responsabilidade social das empresas, tendo como recorte analítico a ONG Teto e as empresas que a financiam. A política social patrocinada por essas empresas atende antes seus próprios interesses do que colaboram para a superação dos problemas sociais. Essas práticas agem na conformação de um padrão de intervenção social nas cidades, corroborando para a perspectiva do espaço (e da cidade) enquanto mercadoria. Levantamos dados secundários e aplicamos entrevistas semiestruturadas com três empresas que entre os anos de 2011 e 2017 contribuíram para o desenvolvimento do trabalho da Teto na condição de parceria estratégica. Constatou-se que a questão social entrou no rol da reprodução capitalista, passando a fazer parte de um modelo de negócios.

This work has as a central objective to understand the capture of the social market through the discourse of corporate social responsibility, having as an analytical cut the NGO Teto and the corporates that finance it. The social policy practiced by these corporates rather serves their own interests than they contribute to overcoming social problems. These practices act in the conformation of a pattern of social intervention in cities that corroborate the perspective of space (and city) as a commodity. We raised secondary data and applied semi-structured interviews with three companies that between the years 2011 and 2017 contributed to the development of the organization's work as a strategic partner. It was found that the social question entered the role of capitalist reproduction, becoming part of a business model.

Este trabajo tiene como objetivo central entender la captura de lo social por el mercado a través del discurso de la responsabilidad social de las empresas, teniendo como recorte analítico la ONG Teto y las empresas que la financian. La política social practicada por esas empresas atiende antes sus propios intereses de lo que colaboran para la superación de los problemas sociales. Estas prácticas actúan en la conformación de un patrón de intervención social en las ciudades que corroborando hacia la perspectiva del espacio (y de la ciudad) como mercancía. Levantamos datos secundarios y aplicamos entrevistas semiestructuradas con tres empresas que entre los años 2011 y 2017 contribuyeron al desarrollo del trabajo de la organización en la condición de socio estratégico. Se constató que la cuestión social entró en el rol de la reproducción capitalista, pasando a formar parte de un modelo de negocios.

Ce travail vise à comprendre la capture du social par le marché à travers le discours de la responsabilité sociale des entreprises, en ayant pour objectif analytique l'ONG Teto et les entreprises qui le financent. La politique sociale parrainée par ces entreprises sert leurs propres intérêts plutôt que de contribuer à surmonter les problèmes sociaux. Ces pratiques contribuent à façonner un modèle d'intervention sociale dans les villes, corroborant la perspective de l'espace (et de la ville) en tant que marchandise. Nous avons collecté des données secondaires et mené des entretiens semi-structurés avec trois sociétés qui, entre 2011 et 2017, ont contribué au développement du travail de Teto en tant que partenaire stratégique. Il a été constaté que la 
question sociale est entrée dans la liste de la reproduction capitaliste, faisant partie d'un modèle économique.

ÍNDICE

Mots-clés: Ville d'affaires; Responsabilité sociale des entreprises; ONG Teto.

Keywords: business-city; Corporate Social Responsibility; NGO Teto.

Palabras claves: Ciudad-negocio; Responsabilidad social empresarial; ONG TETO.

Palavras-chave: Cidade-negócio; Responsabilidade social empresarial; ONG Teto.

\section{AUTORES}

\section{EDMILSON CAMPOS SOARES}

PEB II da Secretaria de Educação do Estado de São Paulo e Mestrando do Programa de PósGraduação em Geografia (PPG) da Universidade Federal Fluminense (UFF), Rio de Janeiro. E-mail: edmilson_soares@outlook.com

\section{ERIKA VANESSA MOREIRA SANTOS}

Profa. Dra. do Núcleo de Estudos Rurais e Urbanos (NERU) da Universidade Federal Fluminense (UFF), Campus de Campos dos Goytacazes, Rio de Janeiro. E-mail: evmgeo@yahoo.com.br 